\title{
Application of Neural Networks to Scheduling Problem including Transportation Time
}

\author{
Qazi Shoeb Ahmad \\ Department of Mathematics \\ Integral University \\ Lucknow (India)
}

\author{
M. H. Khan \\ Department of Mechanical Engineering \\ Galgotias College of Engineering \& Technology \\ Greater Noida (India)
}

\begin{abstract}
This paper presents an approach for finding an optimal schedule of $\mathrm{n}$-jobs and $\mathrm{m}$-machines flowshop scheduling problem involving transportation time between jobs by using neural networks. An algorithm has been given for finding the optimal sequence in scheduling problem without transportation time [2]. Here, this algorithm is applied when transportation times are involved between machines to find the optimal sequence.
\end{abstract}

\section{General Terms}

Flow shop scheduling problem.

\section{Keywords}

Neural networks, flowshop scheduling, transportation time.

\section{INTRODUCTION}

The flowshop sequencing problem is considered as one of the general production scheduling problem in which $\mathrm{n}$ different jobs must be processed by $\mathrm{m}$ machines in the same order. Complete enumeration, integer programming, branch and bound techniques can be used to find the optimal sequences for small size problems but they do not provide efficient solutions for large size problems [3]. The problem of scheduling of $\mathrm{n}$ jobs on two machines arranged in tandem where time required transporting jobs from first machine to another machine was assumed to be negligible [8]. There are practical scheduling situations when certain times are required by jobs for their transportation from one machine to another machine. This situation can be visualized when the machines on which jobs are to be processed are planted at different places and these jobs require additional times in their transplantation from one machine to another machine in the form of loading time, moving time and then unloading time of jobs. Some model $[2,12,14,6]$ have been developed and its application based on object oriented neural network for scheduling problem. Some heuristic algorithms $[4,7,9,11$, $13,1]$ have been used for the $n$-job, m-machine sequencing problem. Artificial neural networks for job shop simulation have been given by [5]. Fuzzy Job sequencing for a flowshop have been given by [9].

The flowshop sequencing problem with the makespan criterion: Sequencing is the process of defining the order in which jobs are to be run on a machine. Scheduling is the process of adding start and finish time information to the job order dictated by the sequence. Essentially, the sequence determines the schedule, since we will assume each job is started on a machine as early as possible, that is, as soon as both the jobs has finished all predecessor operations and the machine has completed all earlier jobs in its sequence.

The flowshop problem sequencing problem is a production planning problem: $\mathrm{n}$ jobs (items, tasks,...) have to be processed in the same sequence on $\mathrm{m}$ machines; the processing time of job $i$ on machine $j$ is given by $p_{i j}(i=1,2, \ldots, n ; j=1,2, \ldots, m)$.These times are fixed, non negative and some of them may be zero if some job is not processed on a machine [13]. The transportation time of job $i$ on machine $j$ to machine $j+1$ is given by $t_{i}(j, j+1)(i=1,2 \ldots, n ; j=1,2, \ldots, m)$. The problem consists of minimizing the time between the beginning of the execution of the first job on the first machine and the completion of the execution of the last job on the last machine, this time is called makespan. In other words, the objective is to find the sequence of jobs minimizing the maximum flow time (makespan) [3].

\section{FORMULATION OF THE PROBLEM}

Formulation of the problem in tabular form is given below:

\begin{tabular}{|c|c|c|c|c|c|c|}
\hline $\begin{array}{c}\text { Job } \\
(i)\end{array}$ & $M_{1}$ & $t_{i}(1,2)$ & $M_{2}$ & $t_{i}(2,3)$ & $\ldots$ & $M_{m}$ \\
\hline 1 & $p_{11}$ & $t_{1}$ & $p_{12}$ & $t_{1}$ & $\ldots$ & $p_{1 m}$ \\
\hline 2 & $p_{21}$ & $t_{2}$ & $p_{22}$ & $t_{2}$ & $\ldots$ & $p_{2 m}$ \\
\hline$\cdot$ & $\cdot$ & $\cdot$ & $\cdot$ & $\cdot$ & $\ldots$ & $\cdot$ \\
\hline$\cdot$ & $\cdot$ & $\cdot$ & $\cdot$ & $\cdot$ & $\ldots$ & $\cdot$ \\
\hline$\cdot$ & $\cdot$ & $\cdot$ & $\cdot$ & $\cdot$ & $\ldots$ & $\cdot$ \\
\hline$n$ & $p_{n 1}$ & $t_{n}$ & $p_{n 2}$ & $t_{n}$ & & $p_{n m}$ \\
\hline
\end{tabular}

\section{ALGORITHM}

Step1. Take the operation times of each job on each machine with transportation time, generate a $n \times m$ dimensional problem.

(If the completion time of a job on a machine is greater than the sum of transportation time from a machine to the subsequent machine and processing time of the subsequent 
machine will be as completion time on first machine otherwise the completion time of job on subsequent machine will be starting time of the next job on that machine).

Step2. Consider all of the combinations of all jobs, produce $n(n-1)$ pairs (two by two).

Step3. Calculate the partial makespan of all pairs by loading the jobs on the machines. Pair $(i, j)$ and pair $(j, i)$ are compared. For the pairs which have smaller completion time, the first job takes the frequency value of 1 , the other job 0 .

By these comparisons $n(n-1) / 2$ frequency values are obtained. If the completion time of the pairs are the same then both jobs takes the frequency value of 1 .

Step4. Sum up the frequency values of all jobs and sort them in decreasing order (This method sequences the jobs in decreasing frequency values order).

Step5. If the jobs have equal frequency values, consider alternative sequences and the sequence which results in less total completion time is optimal sequence.

\section{IMPROVEMENT PHASE}

The job pairs which have equal total completion times are evaluated and the dominant pairs are found. The pairs which have less total machine idleness are considered as dominant. A frequency value of 1 is added to the first job and a frequency value of 1 is subtracted from the other job and a new sequence is generated.

\section{NUMERICAL EXAMPLE}

Consider a flowshop with 4 machines. There are 3 jobs to be scheduled and their processing and transportation times are as follows:

\begin{tabular}{|c|c|c|c|c|c|c|c|}
\hline Job & $M_{1}$ & $t(1,2)$ & $M_{2}$ & $t(2,3)$ & $M_{3}$ & $t(3,4)$ & $M_{4}$ \\
\hline 1 & 20 & 5 & 18 & 3 & 11 & 4 & 5 \\
\hline 2 & 30 & 7 & 14 & 1 & 10 & 2 & 6 \\
\hline 3 & 25 & 6 & 16 & 2 & 08 & 1 & 4 \\
\hline
\end{tabular}

We compare the calculated total completion times for pairs $i j$ and $j i$ for all of the combinations of the jobs:

\begin{tabular}{|c|c|c|c|}
\hline Pair & Completion time & Pair & Completion time \\
\hline 12 & 90 & 21 & 96 \\
\hline 13 & 82 & 31 & 91 \\
\hline 23 & 92 & 32 & 95 \\
\hline
\end{tabular}

Firstly, pair $(1,2)$ and $(2,1)$ are compared. Since pair $(1,2)$ results in less partial makespan, job 1 takes the frequency value of 1 and job 2 takes the frequency value of 0 . By executing these $n(n-1) / 2$ comparisons, we obtain the frequency values for all the jobs.

Frequency value of each job at each comparison

\begin{tabular}{|c|c|c|c|}
\hline \multirow{2}{*}{ Comparison } & \multicolumn{3}{|c|}{ Job } \\
\cline { 2 - 4 } & 1 & 2 & 3 \\
\hline 1 & 1 & 0 & \\
\hline 2 & 1 & & 0 \\
\hline 3 & & 1 & 0 \\
\hline
\end{tabular}

Now, we find the sum of the frequency values for all the jobs. The frequency values for each job are given below:

\begin{tabular}{|c|c|}
\hline Job No. & Total of Frequency \\
\hline 1 & 2 \\
\hline 2 & 1 \\
\hline 3 & 0 \\
\hline
\end{tabular}

The frequency values of all jobs are sorted in decreasing frequency value order. The method yields the sequence 1-2-3.

There is only one sequence so the optimal sequence is 1-2-3 with total completion time 112 units.

\section{NOTE}

In the above example there are no job pairs which have equal total completion times. So there is no dominant pair.

\section{CONCLUSION}

This paper provides an algorithm for finding an optimal schedule of $n$-jobs and m-machines flowshop scheduling problem involving transportation time between jobs by using neural networks. An algorithm has been given for finding the optimal sequence in scheduling problem without transportation time [2]. This paper has considered the situation where transportation times are involved between machines. There is a scope of neural network in other cases related to the scheduling problem.

\section{REFERENCES}

[1] Agarwal A., Colak S. and Eryarsoy E., "Improvement heuristic for the flow-shop scheduling problem: An adaptive-learning approach", European Journal of Operational Research, 169 (3), 801-815 (2006)

[2] Aslan Demir, 'Model development and application based on object oriented neural network for scheduling 
problem", DEU Research Fund. Project Nr. 0908.97.07.01 (1999)

[3] Baker K. R., Introduction to sequencing and scheduling, New York, John Wiley

[4] Campell H., Dudek R. and Smith M., "A heuristic algorithm for the n-job, m-machine sequencing problem", Management Science, 16, 630-637 (1970)

[5] Fonseca D. J. and Navaresse D., "Artificial neural networks for job shop simulation", Advanced Engineering Informatics, 16 (4), 241-246 (2002)

[6] Gary R. Weckman, Chandrasekhar V. Ganduri and David A. Koonce, "A neural network job-shop scheduler", Journal of Intelligent Manufacturing, 19:191-201 (2008)

[7] Ho J. C. and Chang Y. L., "A new heuristic for the n-job, m-machine flow-shop problem", European Journal of Operational Research, 52, 194-202 (1991)

[8] Johnson S. M., "Optimal two and three-stage production schedules with set-up times included", Naval Research Logistics Quaterly, 1, 61-68 (1954)
[9] Koulamas, Christos, "A new constructive heuristic for the flowshop scheduling problem", European Journal of Operational Research, 105, 66-71 (1988)

[10] McCahon C.S. and Lee E.S., "Fuzzy Job sequencing for a flowshop", European Journal of Operational Research, 62, 294-301 (1992)

[11] Nawaz M., Enscore E. and Ham I., "A heuristic algorithm for the n-job, m-machine flowshop sequencing problem, Omega, 11, 91-95 (1983)

[12] Sabuncuoglu, Ihsan and Gurgun, Burckaan, "A neural network model for scheduling problems", European Journal of Operational Research, 93, 288-299 (1996)

[13] Taillard E., "Some efficient heuristic methods for the flowshop sequencing problem", European Journal of Operational Research, 47, 65-74 (1990)

[14] Yu H. and Liang W., "Neural network and genetic algorithmbased hybrid approach to expanded job-shop scheduling", Computers and Industrial Engineering, 39 (3-4), 337-356 (2001) 